\title{
Sudanese Clays for Heterogenous Methanolysis of Castor Oil
}

Abdul Rahim Yacob* and Ahmed Mahgoub Saied Mohmedahmed

${ }^{*}$ Department of Chemistry, Faculty of Science, University Teknologi Malaysia, UTM Skudai, Malaysia

*Corresponding author: Abdul Rahim Yacob, Department of Chemistry, Faculty of Science, University Teknologi Malaysia, UTM Skudai, Malaysia, Tel: (60) 137428830; E-mail: manrahim@kimia.fs.utm.my

Received date: Sep 13, 2017; Accepted date: Sep 28, 2017; Published date: Oct 05, 2017

Copyright: (C) 2017 Yacob AR, et al. This is an open-access article distributed under the terms of the Creative Commons Attribution License, which permits unrestricted use, distribution and reproduction in any medium, provided the original author and source are credited.

\begin{abstract}
Objective: To modify two Sudanese clays, called Jourdiqua and Jabbalmarra, with different loading of $\mathrm{HCl}, 0.1$ $\mathrm{M}, 0.2 \mathrm{M}, 0.3 \mathrm{M}, 0.4 \mathrm{M}, 0.5 \mathrm{M}$ and $1.00 \mathrm{M}$ in order to increase their catalytic activities and then used in methanolysis of castor oil.

Methods/Statistical analysis: Both raw and modified clay samples were used as catalysts under reaction conditions; $5 \mathrm{wt} \%$ of catalyst to oil, molar ratio of methanol to oil of $27: 1,4 \mathrm{~h}$ reaction time and temperature of $67^{\circ} \mathrm{C}$. The unmodified and modified clay samples were characterized by, thermogravimetric analysis-differential thermogravimetric (TGA-DTG), Brunauer-Emmett-Teller (BET), inductively coupled plasma-emission spectroscopy (ICP-ES), atomic absorption spectroscopy (AAS), X-ray powder diffraction (XRD), Fourier transform infra-red (FTIR) and field electron scanning emission microscopy (FESEM).

Finding: Application/Improvement: BET analysis showed increase in specific surface area for both Jourdiqua and Jabbalmarra clays. Elemental analysis by ICP-ES showed decrease content in elements of $\mathrm{Al}, \mathrm{Mg}, \mathrm{Na}$ and $\mathrm{K}$ for both clays, due to the acid leaching. The biodiesel conversion was monitored using nuclear magnetic resonance (NMR) spectroscopy. An increase in conversion was observed for Jourdiqua clay from $51 \%$ to $90 \%$ when treated with $0.5 \mathrm{M} \mathrm{HCl}$, the optimized concentration for the modification, while for Jabbalmarra $22.5 \%$ conversion was obtained with raw clay and after modification gave conversion of $82 \%$ in reaction conditions of temperature $65^{\circ} \mathrm{C}$, reaction time of $4 \mathrm{~h}$, molar ratio of methanol to oil of $18: 1$ and catalyst loading of $9 \%$. It was observed that acid modification with $0.5 \mathrm{M} \mathrm{HCl}$ have improved tremendously the catalytic capability of the raw clays.
\end{abstract}

Keywords: Modification; Characterization; Catalyst; Transesterification; Sudanese clays

\section{Introduction}

Biodiesel is the methyl esters of fatty acids develop as an alternative to fossil fuels. The strongest motivation factor is the concern about global pollutant. Biodiesel has many environmental benefits which include less greenhouse effect, less air and soil pollution, leading to less health risk. Today, over 85 biodiesel production plants are working world wide, the biodiesel is produced by transesterification of vegetable oils and fats with short chain alcohol (methanol or ethanol) [1].

In recent years, the development of alternative fuel like bioethanol and biodiesel from renewable sources has received considerable attention. Homogeneous catalysts are used but they have problems such as leaching, saponification which require washing and this cause release of waste water. Heterogeneous solid catalysts such as zeolites and clay minerals have been developed as substitutes for homogeneous catalysts and have benefit of being easy to recover and the process required no washing [2].

It is very important to find cheap raw materials without competition with arable land and food for the development of biofuel, such as nonedible oil, waste oil and fats. Castor oil is a very promising source of biodiesel, a colorless or pale yellowish oil extracted from seeds of castor oil plant, castor (Ricinus communis $L$ ) is cultivated around the world because of the commercial importance of its oil which is used in the manufacture of a number of industrial chemicals like surfactants, grease and lubricants, specialty soap, surface coating and cosmetic. Castor seed has an oil content of $42 \%$ to $48 \%$, castor plant grows well under hot and humid tropical conditions and has a growing period of 4 to 5 months. Castor oil has density of $950 \mathrm{~kg} / \mathrm{m} 3$ at $15^{\circ} \mathrm{C}$ and molecular weight of $927 \mathrm{~g} / \mathrm{mol}$. The main fatty acid present in castor oil is ricinoleic acid with percentage of about $90 \%$ [3].

Clay minerals can be more acidic if it is modified with dilute hydrochloric acid. The acid modification of the clay improves its catalytic activity. The aim of this study is to produce biodiesel from vegetable oil (castor oil) using clays as acid catalyst.

\section{Experimental}

\section{Materials}

The starting clay samples are natural Sudanese clays; Jourdiqua (black clay) from north of Sudan (Suba) and Jabbalmarra (white clay) from the west of Sudan at Darfur state, Nyala city Jabbalmarra region. Castor oil was purchased from Indian shop in Skudai, Johor Bahru. Methanol of purity $>99 \%$, hydrochloric acid $37 \%(w / w)$ and potassium hydroxide were obtained from Aldrich. Deionized water is used for the preparation of solution. All chemicals are of analytical grade and used without further purification.

The clay samples were dried in an oven at $80^{\circ} \mathrm{C}$ overnight, grinded and sieved through 200 mesh $(75 \mu)$ sieve to obtain $0.075 \mathrm{~mm}$ particle size and kept in sample bottles [4]. 


\section{Modification of clays}

Both clay samples were calcined at $450^{\circ} \mathrm{C}$ for $4 \mathrm{~h}$ then cooled in a desiccator, $10 \mathrm{~g}$ of each sample was weighed and transferred into six different $250 \mathrm{~mL}$ double neck round bottom flask, followed by addition of $100 \mathrm{ml}$ of $0.1 \mathrm{M}, 0.2 \mathrm{M}, 0.3 \mathrm{M}, 0.4 \mathrm{M}, 0.5 \mathrm{M}$ and $1.00 \mathrm{M} \mathrm{HCl}$ solutions. The mixture was refluxed at $90^{\circ} \mathrm{C}$ under stirring at $300 \mathrm{rpm}$ for $3 \mathrm{~h}$, cooled to room temperature, then filtered and washed with distilled water. The sample is then dried in an oven at $80^{\circ} \mathrm{C}$ overnight and kept in sample bottles. The clay samples are denoted; JB, JB0.1, JB0.2, JB0.3, JB0.4, JB0.5 and JB1 and JQ, JQ0.1, JQ0.2, JQ0.3, JQ0.4, JQ0.5 and JQ1 for raw Jabbalmarra and Jourdiqua and acid modified samples using $0.1 \mathrm{M}, 0.2 \mathrm{M}, 0.3 \mathrm{M}, 0.4 \mathrm{M}, 0.5 \mathrm{M}$ and $1.0 \mathrm{M} \mathrm{HCl}$, respectively.

\section{Characterization of clays}

The ICP-ES analysis was performed by digesting about $1 \mathrm{~g}$ of the clay sample using HF acid and aqua regia and diluting to $250 \mathrm{ml}$ with distilled water, the solution is then analyzed. The XRD analysis was carried out on a Bruker D8 having Siemens diffractometer D5000 with $\mathrm{Cu}-\mathrm{Ka}$ radiation $(40 \mathrm{kV}, 40 \mathrm{~mA}, \lambda=1.5406 \AA$ ) (USA), the sample was scanned at the rate of $0.05 \mathrm{~s} / \mathrm{step}$ and $2 \theta$ range of $10-70 \mathrm{o}$. The morphology was determined using field emission electron microscope (FESEM) (Supra TM 35 VP operating at 10kV) (Germany). The TGDTG analysis was carried out using Perkin Elmer Simultaneous Thermal Analyzer (STA 8000) (USA) in the temperature range of $50^{\circ} \mathrm{C}$ to $1200^{\circ} \mathrm{C}$ and heating rate of $10^{\circ} \mathrm{C} / \mathrm{min}$. Nitrogen adsorptiondesorption was used to determine the surface area at $-196^{\circ} \mathrm{C}$ using Micromeritics Pulse Chemisorb 2705 (USA), prior to analysis all samples were dehydrated and degassed for $1 \mathrm{hr}$ at $473 \mathrm{~K}$ under nitrogen gas flow condition. The samples were then evacuated to $10^{-2}$ Torr and immersed in the liquid nitrogen. Perkin Elmer 1650 InfraRed Spectrometer (USA) was used for FTIR analyses of samples in the range of $4000 \mathrm{~cm}^{-1}$ to $400 \mathrm{~cm}^{-1}$. The $\mathrm{pH}$ was measured using EUTECH INSTRUMENT $\mathrm{pH}$ Tutor (Singapore), the clay was mixed with deionized water in the ratio of 1:1, the measurement was performed by placing the glass electrode in the clay mixture at room temperature. The density of the clay was determined by taking a known amount using metal ring pressed into the clay and the weight is determined after drying. From the weight and volume the density is obtained. Moisture content of the clay sample was determined by weighing known amount of clay and placing it in an oven, the sample was dried until a constant weight is obtained. From the weight loss, the moisture content of the clay sample was calculated.

\section{Acidic test (Back titration)}

About $0.2 \mathrm{~g}$ of the clay sample was taken in small tube and $10 \mathrm{ml}$ of distilled water was added and left overnight and then centrifuged at $3000 \mathrm{rpm}$ for $15 \mathrm{~min}$, the mixture was filtered and transferred to a conical flask, $10 \mathrm{ml}$ of $0.05 \mathrm{M} \mathrm{KOH}$ was added to the filtrate, followed by 3 drops of phenolphthalein indicator and titrated against $0.02 \mathrm{M}$ $\mathrm{HCl}$ solution to the end point.

\section{Transesterification process}

The Transesterification reaction of the castor oil was conducted, using the raw and modified clays in $250 \mathrm{ml}$ double neck round bottom flask with methanol to oil molar ratio of $18: 1$, catalyst loading $5 \%$, reaction time of $3 \mathrm{~h}$ at $67^{\circ} \mathrm{C}$, under stirring at $300 \mathrm{rpm}$. After completion of the reaction the products are allowed to settle overnight and centrifuged at $3000 \mathrm{rpm}$ for $15 \mathrm{~min}$. Three layers were observed; upper layer of methanol was distilled, while the middle layer of biodiesel and the lower layer of glycerol and settled catalyst were separated using separation funnel. Biodiesel was dried over sodium sulfate and then characterized by NMR technique.

\section{Results and Discussion}

\section{Physical characterization and TGA-DTG}

Figure 1 depicts the TGA-DTG curves of JB and JQ clays. For the JB clay, the first weight loss was around $60^{\circ} \mathrm{C}$, due to the evaporation of absorbed water molecules between layers of clay. The loss at this temperature was about $8 \%$. The second weight loss was around $275^{\circ} \mathrm{C}$ of around $6.32 \%$, which may be due the evaporation of carbonate, bicarbonate and other volatile species. The third loss was around $750^{\circ} \mathrm{C}$ of about $4.7 \%$; this may be due the loss of volatile species and hydoroxide structures, present between clay layers.

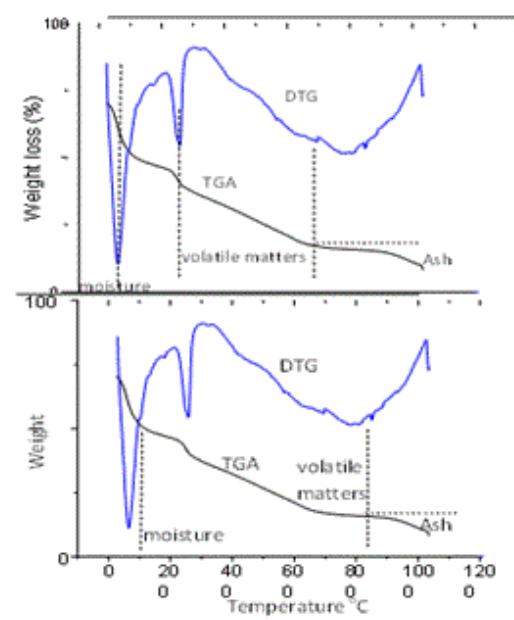

Figure 1: Thermogram of clay samples.

For the JQ clay, the first loss was at $60^{\circ} \mathrm{C}$, also due to the evaporation of water molecules between layers, which is about $16 \%$. The second loss was around $270^{\circ} \mathrm{C}$, may be due to the liberation of carbonates, bicarbonates and some volatile species from the sample, the loss at this temperature is about $6.32 \%$. The third loss is around $4.2 \%$ at $690^{\circ} \mathrm{C}$ and may be due to the loss of volatile species from the simple [5].

From the result it can be seen that JQ clay has high percentage of moisture of about $16 \%$ indicating the availability of swelling water molecules, pointing to its plasticity and strength. High densities were observed for both clays making them suitable for many applications such as the brick production. Loss on ignition is high for the JQ clay reaching about $19 \%$, this may be due to the high amounts of volatile species present in the clay, such as carbonate and bicarbonate, which make this clay not suitable as refractory clay. On the other hand, the JB clay has low value of ignition loss of about $10.33 \%$, which make it suitable to be regarded as refractory clay. The high $\mathrm{pH}$ value of JQ clay of 11.13 can be attributed to its high basicity. This may be due to the high percentage of metal carbonate in the sample that hydrolyzed to form basic solution. The combustible volatile matter content of the JQ clay was high as evidence from the high ash content, while it was low 
Citation: Yacob AR, Mohmedahmed AMS (2017) Sudanese Clays for Heterogenous Methanolysis of Castor Oil. J Pharmacovigil 5: 241. doi:

Page 3 of 6

for the JB clay. The five physical parameters determined for the two clays are listed in Table 1.

\begin{tabular}{|l|l|l|l|l|l|}
\hline Clay & pH & Moisture (\%) & $\begin{array}{l}\text { Loss on } \\
\text { ignition }(\mathbf{\%})\end{array}$ & $\begin{array}{l}\text { Ash content } \\
(\mathbf{\%})\end{array}$ & $\begin{array}{l}\text { Density } \\
(\mathbf{g} / \mathbf{m L})\end{array}$ \\
\hline JB & 6.61 & 8 & 10.33 & 6.32 & 1.42 \\
\hline JQ & 11.1 & 16 & 18.72 & 11.62 & 1.12 \\
\hline
\end{tabular}

Table 1: Physical characterization for the clay samples.

\section{Elemental analysis}

The chemical compositions of the two clays were determined using (ICP-ES) and atomic absorption spectroscopy and the result is shown in Table 2. The low content of alumina for the two clays makes them unsuitable for use as high melting clay. The ratio of silicate to alumina $(\mathrm{SiO} / \mathrm{Al} 2 \mathrm{O} 3)$ in both clays is greater than one, making them suitable for zeolite synthesis. The high silicate content of JB clay makes it appropriate for the production of floor tiles.

The high content of silica and alumina compared with other oxides in JB clay suggests that it is kaolinite. For the JQ clay, its high sodium content may be due to the high percentage of carbonate and bicarbonates as can be seen from the presence of peak around 1720 $\mathrm{cm}^{-1}$ in FTIR spectra due to carbonates, as well as from the high weight loss due to the liberation of carbonate in the TGA result.

\begin{tabular}{|c|c|c|}
\hline Elements & Raw JB (\%) & Raw JQ (\%) \\
\hline $\mathrm{Si}$ & 75.239 & 14.12 \\
\hline $\mathrm{Al}$ & 10.24 & 4.17 \\
\hline $\mathrm{Ba}$ & 0.391 & 1.61 \\
\hline $\mathrm{Mg}$ & 0.315 & 1.15 \\
\hline $\mathrm{Li}$ & 0.201 & 1.02 \\
\hline $\mathrm{Fe}$ & 3.25 & 20.5 \\
\hline $\mathrm{Rb}$ & 0.063 & 0.3 \\
\hline $\mathrm{Ga}$ & 0.037 & 0.14 \\
\hline As & 0.019 & 0.22 \\
\hline $\mathrm{Pb}$ & 0.018 & 0.002 \\
\hline $\mathrm{Sr}$ & 0.015 & 0.12 \\
\hline Cs & 0.007 & 0 \\
\hline $\mathrm{Zn}$ & 0.007 & 0.04 \\
\hline $\mathrm{Se}$ & 0.004 & 0.001 \\
\hline $\mathrm{Ni}$ & 0.003 & 0.013 \\
\hline $\mathrm{Cu}$ & 0.001 & 0.009 \\
\hline $\mathrm{Ca}$ & 2.55 & 10.4 \\
\hline $\mathrm{Na}$ & 6.641 & 41.5 \\
\hline
\end{tabular}

Table 2: Elemental analysis for the two raw clays.
This makes it suitable as traditional medicine for stomach ache especially in Sudan. Also the high sodium content make it suitable as an ion exchanger, for purification of water. Other oxides present in both clays make them suitable for ion exchange process and can increase their acidity and basicity. After acid treatment many elements were leached out as a result, their percentage decreased in the samples, while the percentage of silica and alumina increased, the big difference of the ingredient composition of the two clays, due to their origin, JB clay is contain kaolin and quartz, which are resulted from deposition of volcanic ash that rich in silica and alumina, while JQ contains momtomorillonit clay, which is resulted from deposition of volcanic ash that rich in iron, sodium, calcium and magnesium [6].

\section{Fourier transform infrared spectroscopy (FTIR)}

Figure 2 shows the spectra for the raw and modified JB and JQ clays, respectively. The layer structure reveals four well resolved $[\mathrm{OH}]$ bands in the IR spectra.

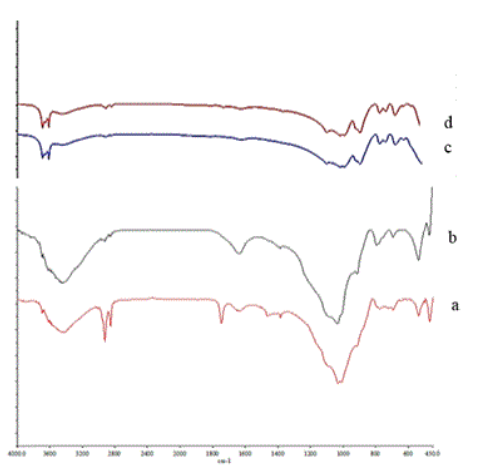

Figure 2: FTIR spectra of (a) JQ $\mathrm{JQ}_{1}$; (b) JQ; (c) JB; (d) JB . $^{\circ}$

\begin{tabular}{|l|l|}
\hline Wave number $\left(\mathbf{c m}^{-1}\right)$ & Assignment \\
\hline 3438.73 & Stretching vibration of $\mathrm{OH}$ of water. \\
\hline 1607.74 & OH deformation of water. \\
\hline 1440.56 & Traces of carbonate \\
\hline 1174.39 & Si-O stretching. \\
\hline 1024.26 & Si-O stretching. \\
\hline 940 & Al-Al-OH deformation \\
\hline 892.74 & Traces of carbonate. \\
\hline 858.81 & Al-O deformation \\
\hline 787.48 & Al-O-Si deformation \\
\hline 698.55 & Si-O stretching \\
\hline 481.76 & Si-O-Si deformation. \\
\hline
\end{tabular}

Table 3: Observed bands for the raw JB and JQ clay.

Three of these bands are assigned to the stretching vibrations of surface hydroxyl groups at $3620 \mathrm{~cm}^{-1}, 3654 \mathrm{~cm}^{-1}$ and $3696 \mathrm{~cm}^{-1}$ while the fourth at $3456 \mathrm{~cm}^{-1}$ is attributed to the vibrations of the inner 
Citation: Yacob AR, Mohmedahmed AMS (2017) Sudanese Clays for Heterogenous Methanolysis of Castor Oil. J Pharmacovigil 5: 241. doi:

hydroxyl groups. Bands at $694 \mathrm{~cm}^{-1}, 795 \mathrm{~cm}^{-1}, 913 \mathrm{~cm}^{-1}$ and $936 \mathrm{~cm}^{-1}$ are additional bands associated with surface hydroxyls.

The band near $467 \mathrm{~cm}^{-1}$ is due to the Si-O-Si deformation and that at $541 \mathrm{~cm}^{-1}$ is due to $\mathrm{Si}-\mathrm{O}-\mathrm{Al}$ deformation. While bands at 694 and 795 $\mathrm{cm}^{-1}$ are due to the Si-O stretching, band at $1031 \mathrm{~cm}^{-1}$ is attributed to the $\mathrm{V}[\mathrm{Si}-\mathrm{O}]$ planar stretching. The peaks assignments are presented in Table 3.

When the clay samples are modified with different concentrations of $\mathrm{HCl}$, two new bands at $2924 \mathrm{~cm}^{-1}$ and $2855 \mathrm{~cm}^{-1}$ appeared which may be related to the stretching vibrations of $\mathrm{H} 2 \mathrm{O}$ and $\mathrm{OH}$ groups due to the clay hydrolysis by aqueous solution of $\mathrm{HCl}$. The rest of the hydroxyl groups bands shifted to the lower frequency after acid modification [7]. For JQ, after acid modification three new bands appeared. This may be due to the stretching vibrations of inner hydroxyls formed after acid modification; these bands are at $2958 \mathrm{~cm}^{-1}, 2925 \mathrm{~cm}^{-1}$ and $2825 \mathrm{~cm}^{-1}$ that can be attributed to the stretching vibrations of $\mathrm{H} 2 \mathrm{O}$ and $\mathrm{OH}$ groups. Also new band at $1450 \mathrm{~cm}^{-1}$ related to Lewis acid was appeared. The rest of the hydroxyl groups bands were shifted to the lower frequency [8].

\section{X-rays Diffraction analysis (XRD)}

Figure 3 shows the diffractogram of raw JQ, peaks at $2 \theta$ of 21.00 (4.12 $\AA$ ), 26.66 (3.33 $\AA$ ) and 28.00 (3.19 $\AA)$ corresponding to [ $\left.\begin{array}{lll}1 & 1 & 0\end{array}\right]$, [6 $\left.0 \begin{array}{ll}0 & 0\end{array}\right]$ and $\left[\begin{array}{lll}1 & 1 & 1\end{array}\right]$ planes, respectively, were observed indicating the presence of montmorillonite [9]. The peaks at $2 \theta$ values, 20.00 (4.20 $\AA$ ), $26.66(3.33 \AA)$ and 36.50 (2.475 $\AA$ ) equivalent to the of [ $\left[\begin{array}{lll}1 & 1 & 1\end{array}\right],\left[\begin{array}{lll}1 & 2 & 0\end{array}\right]$ and $\left[\begin{array}{lll}1 & 1 & 2\end{array}\right]$ planes respectively, indicates the presence of muscovite, while peaks at $2 \theta$ of $26.66(3.34 \AA), 50.00$ (1.816 $\AA$ ) and $60.00(1.514$ $\AA$ A), corresponding relatively to, 0006,112 and 2111 planes, designating the presence of quartz.

The main clay minerals in JQ clay are therefore montmorillonite, muscovite and quartz [10]. After acid modification the diffractogram showed some loss of crystallinity, due to the removal of octahedral cations, resulting in destruction of some octahedral layers (Figures 4-7).

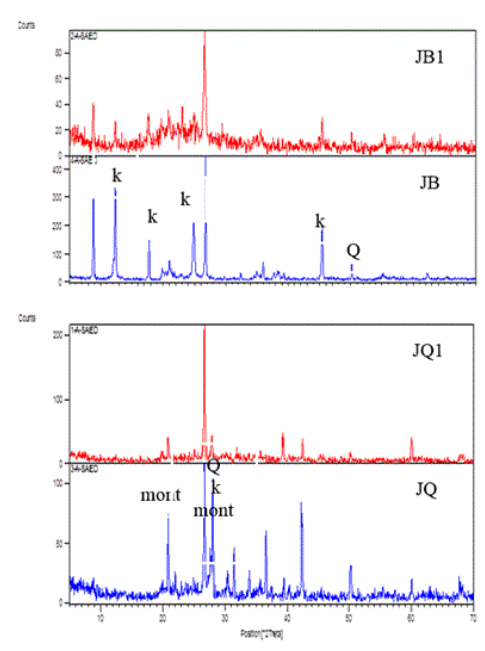

Figure 3: XRD diffractograms of unmodified and modified clays, mont: montmrillonite; k: kaolin; Q: quartz.

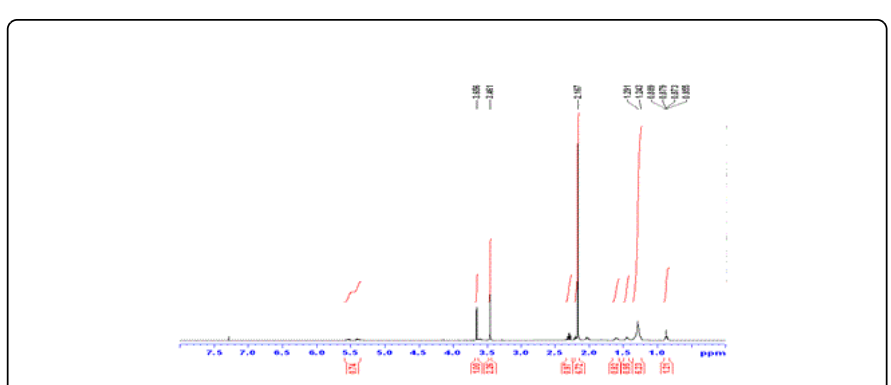

Figure $4:{ }^{1} \mathrm{H}$ NMR spectrum of biodiesel from castor oil in $\mathrm{CDCl} 3$, catalyzed by raw jourdiqua clay, conversion $51 \%$.

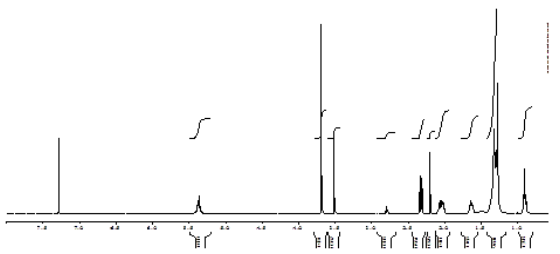

Figure 5: ${ }^{1} \mathrm{HNMR}$ spectrum of biodiesel from castor oil in $\mathrm{CDCl}_{3}$, catalyzed by $0.5 \mathrm{M} \mathrm{HCl}$ modified jourdiqua clay, conversion $90 \%$.

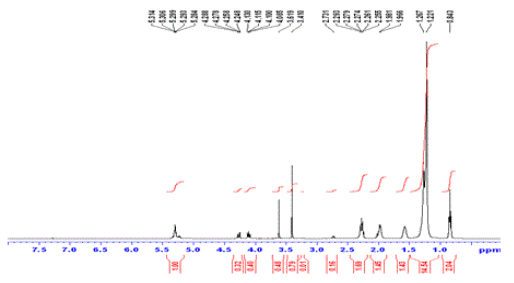

Figure 6: ${ }^{1} \mathrm{HNMR}$ spectrum of biodiesel from castor oil in $\mathrm{CDCl} 3$, catalyzed by raw Jabbalmarra clay conversion $22.5 \%$.

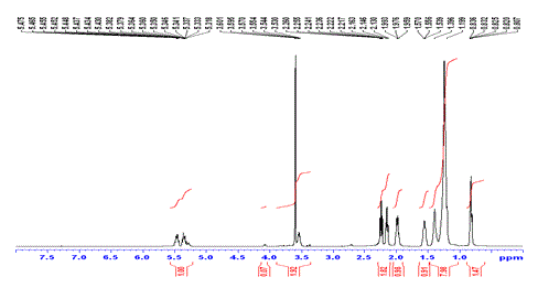

Figure 7: 1HNMR spectrum of biodiesel from castor oil in $\mathrm{CDCl} 3$, catalyzed by $0.5 \mathrm{M} \mathrm{HCl}$ modified Jabbalmarra clay, conversion $82 \%$.

From the diffractogram of raw JB, peaks at $2 \theta$ of $12.41(7.14 \AA)$, $17.91(4.97 \AA), 21.25(4.18 \AA)$ and $24.85 \theta(3.576 \AA)$, related to the planes of [0 $\left.\begin{array}{ll}0 & 0\end{array}\right],\left[\begin{array}{lll}1 & 0 & 0\end{array}\right],\left[\begin{array}{lll}1 & 1 & 1\end{array}\right]$ and [ $\left[\begin{array}{lll}0 & 0 & 2\end{array}\right]$, respectively indicate the presence of kaolin. The peaks at $31.10(3.3 \mathrm{~A}), 26.66(3.34 \AA)$ and 50.00

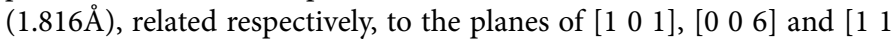
$2]$, were observed indicating the presence of quartz in JB. Hence, the main minerals in JB clay are kaolin and quartz. After acid modification 
Page 5 of 6

the clay had lost more of its crystallinity due to removal of some of its octahedral cations [11].

\section{Acidic back titration}

Acidity test was carried out before and after acid modification to measure the catalytic activity of the clay samples. The acidity of clay samples were determined and listed in Table 4.

Increase in the number of active sites was observed for the two clay samples after acid treatment due to ion exchange and this was confirmed by the FTIR spectra of the clay, which shows appearance of the band at $1450 \mathrm{~cm}^{-1}$ related to Lewis acid. JQ gained more acid sites than JB due to its higher cation exchange capacity (C.E.C) compared to that of JB clay [12].

\begin{tabular}{|l|l|}
\hline Catalyst & Number of acid sites $(\mathbf{m m o l} / \mathbf{g})$ \\
\hline JQ & 0.125 \\
\hline JQ1 & 0.523 \\
\hline JB & 0.115 \\
\hline JB1 & 0.245 \\
\hline
\end{tabular}

Table 4: Acid sites of the catalysts before and after modification.

JQ has gained more acid sites than JB and this possibly be attributed to the composition difference in the two clays, because JQ has more higher percentage of exchangeable castions present in the cation exchangeable region than that present in JB [13].

\section{Nitrogen gas adsorption-desorption analysis (BET)}

The two clays were characterized by nitrogen gas adsorption analysis (BET) before and after acid modification.

\begin{tabular}{|l|l|l|l|}
\hline Catalyst & $\begin{array}{l}\text { Specific surface } \\
\text { area } \\
\left(\mathbf{m}^{2} / \mathbf{g}\right)\end{array}$ & $\begin{array}{l}\text { Sefore } \\
\text { Specific surface } \\
\text { area after }\left(\mathbf{m}^{2} / \mathbf{g}\right)\end{array}$ & $\begin{array}{l}\% \text { change in } \\
\text { specific surface } \\
\text { area }\end{array}$ \\
\hline JQ & 12.12 & 54.65 & 350.91 \\
\hline JB & 3.75 & 7.78 & 107.47 \\
\hline
\end{tabular}

Table 5: Specific surface area of the two clays before and after modification.

\begin{tabular}{|l|l|}
\hline Peaks in ppm & Assignment \\
\hline $0.98-1.00$ & Terminal methyl protons $\mathrm{C}-\mathrm{CH}_{3}$ of triglycerides chain \\
\hline $1.20-1.40$ & Methyl group protons of remaining methanol $\mathrm{CH}_{3} \mathrm{OH}$ \\
\hline $1.50-1.75$ & $\beta$ methylene protons, $\mathrm{CH}_{2}-\mathrm{C}_{-}-\mathrm{CO}_{2} \mathrm{Me}$ \\
\hline $2.3-2.4$ & a methylene protons of esters $\mathrm{CH}_{2}-\mathrm{CO}_{2}-\mathrm{Me}$ \\
\hline 3.49 & Methyl group protons of remaining methanol $\mathrm{CH}_{3} \mathrm{OH}$ \\
\hline 3.66 & Methoxy protons of biodiesel-O- $\mathrm{CH}_{3}$ \\
\hline $5.31-5.36$ & Olefinic protons $\mathrm{CH}_{2}=\mathrm{CH}_{2}$ \\
\hline
\end{tabular}

Table 6: NMR assignment of biodiesel from castor oil.
The heat and acid treatment affect the surface area of clays causing increase in surface area due to the removal of octahedral cations and extending the spaces between clays layers. The surface area as presented in Table 5 was found to increase from $3.75 \mathrm{~m}^{2} / \mathrm{g}$ to $7.78 \mathrm{~m}^{2} / \mathrm{g}$ for JB, while for JQ the increment is from $12.12 \mathrm{~m}^{2} / \mathrm{g}$ to $54.64 \mathrm{~m}^{2} / \mathrm{g}$ (Tables 6, 7).

\begin{tabular}{|l|l|l|}
\hline HCI Modified clays (M) & $\begin{array}{l}\text { Biodiesel yield from JQ } \\
(\%)\end{array}$ & $\begin{array}{l}\text { Biodiesel yield from } \\
\text { JB (\%) }\end{array}$ \\
\hline 0 & 71 & 20 \\
\hline 0.1 & 74.31 & 30.22 \\
\hline 0.2 & 79.53 & 39.41 \\
\hline 0.3 & 81.88 & 50.54 \\
\hline 0.4 & 84.71 & 60.5 \\
\hline 0.5 & 90.85 & 70.22 \\
\hline 1 & 82.82 & 68.13 \\
\hline
\end{tabular}

Table 7: Percentage yield of biodiesel using the raw and acid modified clay catalysts.

\section{Conclusion}

From the results of characterization of the two clays, the main minerals in JB were identified to be kaolinite and quartz, while montmorillonite, muscovite and quartz are present in JQ. The result further revealed that JB is rich in silica and alumina, while JQ is very rich in sodium, this gives it high basicity that resulted in high biodiesel yield even before the acid modification. Both clay samples are rich in metal cations. Acid treatment of the clay samples resulted in an increased in acid sites and surface area which leads to the increase in their catalytic activities. The percentage yield of biodiesel was found to increase with increase in acid concentration. Clay modified with $0.5 \mathrm{M}$ $\mathrm{HCl}$ give the highest biodiesel yield of 90.85 and $70.22 \%$ for both JB and $\mathrm{JQ}$, respectively.

\section{References}

1. Kloprogge JT, Duong LV, Frost RL (2005) Synthesis and characterization of pillared clays and related materials for biodiesel production. Environmental Geology 47: 967-981.

2. Centi G, Perathoner S (2008) Catalysis by layered materials: A review. Microporous Mesoporous Mater 107: 3-15.

3. Varma MN, Madras G (2007) Synthesis of biodiesel from castor oil in supercritical fluids. Ind Eng Chem Res 46: 1-6.

4. Lotero E, Liu Y (2005) Synthesis of biodiesel via, acid catalysis. Industrial and Engineering Chemistry Research, 44: 5353-5363.

5. Varadwaj GBB, Parida K, Nyamori VO (2016) Transforming inorganic layered montmorillonite into inorganic-organic hybrid materials for various applications: A brief overview. Inorg Chem Front 3: 1100-1111.

6. Srinivasan R (2011) Advances in application of natural clay and its composites in removal of biological, organic and inorganic contaminants from drinking water. Adv Mater Sci Eng 2011: 1-11.

7. Zhao LI, Zhou CH, Wang J, Tong DS, Yu WH (2015) Recent advances in clay mineral-containing nanocomposite hydrogels. Soft Matter 11: 9229-9246.

8. Benhammou A, Yaacoubi A, Nibou L, Bonnet JP, Tanouti B (2011) Synthesis and characterization of pillared stevensites: Application to chromate adsorption. Environ Technol 32: 363-372. 
Citation: Yacob AR, Mohmedahmed AMS (2017) Sudanese Clays for Heterogenous Methanolysis of Castor Oil. J Pharmacovigil 5: 241. doi: 10.4172/2329-6887.1000241

Page 6 of 6

9. $\quad$ Eze KA, Nwadiodbu JO, Nwankere ET (2012) Effect of Acid Treatment on the Physicochemical Properties of Kaolin Clay. Arch Appl Sci Res 4: 792-794.

10. Restricted access

11. Sakharov BA, Drits VA, McCarty DK, Walker GM (2016) Modeling powder $\mathrm{x}$-ray diffraction patterns of the clay minerals society kaolinite standards: kga-1, kga-1b and kga-2. Clays and Clay Minerals 64:10.
12. Gerpen JV (2005) Biodiesel processing and production. Fuel Proc Technol 86: 1097-1107.

13. Rezende MJC, Pereira MSC, Santos GFN, Aroeira GOP, Albuquerque TC, et al. (2012) Preparation, characterization and evaluation of Brazilian clay-based catalysts for used in esterification reaction. J Braz Chem Soc 23: $1209-1215$ 